\title{
Year-to-year Consistency of Harvest Data in Raspberry Breeding Plots
}

\author{
Patrick P. Moore ${ }^{1}$ \\ Washington State University, Puyallup Research and Extension Center Puyallup, WA 98371
}

\begin{abstract}
AdDITIONAL INDEX words. Rubus idaeus, stability
ABSTRACT. Harvest data from the first and second harvest seasons were compared for 264 plots in six red raspberry (Rubus idaeus L.) plantings established from 1987 to 1992 to determine year-to-year consistency of harvest data. Midpoint of harvest had the largest correlation coefficient $(r=0.81, n=264)$, followed by fruit mass $(r=0.76)$ and fruit firmness $(r=$ $0.47)$. The relationship between the first and second harvest seasons was weaker for yield $(r=0.33)$ and percent fruit rot $(r=0.24)$. Basing the correlation coefficients on genotype means did not greatly improve the consistency of data. Inconsistency of harvest data suggests that selections should not be discarded because of low yields after a single harvest season but should be evaluated for at least 2 years.
\end{abstract}

Summer fruiting red raspberry produces only vegetative canes (primocanes) in the year of planting. These canes produce the first crop the following season. In our research plots, using small greenhouse propagated plants, the first crop is usually small and no data are collected. Harvest data are collected the third and fourth growing seasons after planting. Collecting harvest data is labor intensive, and genotypes are eliminated from evaluation as quickly as possible. Eliminating genotypes from consideration based on the first harvest season makes the implicit assumption that one season would accurately predict the performance of the selection in other seasons.

In a previous study of 'Willamette' clones, data from one harvest season was compared with data in the next season (Moore et al., 1989). The yield from one harvest season was not significantly correlated with the yield in the next harvest season $(r=0.07$, $\mathrm{n}=10$ ); however, fruit mass and midpoint of harvest were significantly correlated between seasons $(r=0.72, \mathrm{n}=10$ for both). Other studies have shown large fluctuations in yield for raspberry genotypes from year to year (Fejer, 1973) and that raspberry genotypes performed differently not only among locations but also between years (Dale and Daubeny, 1985).

Harvest data collected each year in this breeding program are yield, fruit mass, fruit firmness, fruit rot, and midpoint of harvest. Our objective was to determine the consistency of harvest data between the first and second harvest seasons.

\section{Materials and Methods}

Research plantings established at Washington State Univ. Puyallup Research and Extension Center from 1987 to 1992 were harvested the third and fourth growing seasons after planting (first and second harvest seasons, respectively). Each planting consisted of three replications of three plant plots at 0.92 -m spacing within the row and $2.44 \mathrm{~m}$ between rows. Plots were managed according to commercial guidelines (Scheer and Garren, 1987). Plots were

Received for publication 17 June 1996. Accepted for publication 21 Nov. 1996. H/LA Paper no. 96-5. Washington State Univ., College of Agriculture and Home Economics, Pullman project no. 0640. Partially supported by a grant from the Washington Red Raspberry Commission. The cost of publishing this paper was defrayed in part by the payment of page charges. Under postal regulations, this paper therefore must be hereby marked advertisement solely to indicate this fact. ${ }^{1}$ Associate horticulturist. treated with metalaxyl in the fall and spring of each year to control root rot. Dinoseb was used for primocane suppression for plants in their third and fourth growing seasons. After 1990, no primocane suppression was practiced in the third growing season, and oxyflurofen was used in the fourth growing season. No pesticides were used to control fruit rot or insects.

Each plot was hand-harvested one to two times weekly. Data collected from each harvest were total yield, fresh mass of rotten fruit, fresh mass of 25 fruit, and firmness of five fruit (Robbins and Sjulin, 1986). Fruit mass was determined as the weighted mean for the season of the 25-fruit sample from each harvest. The midpoint of harvest was calculated from the cumulative yield.

Each planting included selections and cultivars. Plants were tested for raspberry bushy dwarf virus and tobacco streak virus by ELISA; plots testing positive were removed. Other genotypes were eliminated from evaluation based on fruit evaluation in the first harvest season. Only data from genotypes present in all three plots in both harvest seasons were included in the study. Several genotypes were included in more than one planting. Data from 234 plots representing 67 genotypes were used in this study.

All five variables were analyzed by analysis of variance (ANOVA) for each planting individually and for all plantings combined, with genotype, year, and genotype $\times$ year as sources of variation. Correlation coefficients were calculated between the harvest data in the first and second harvest season for each planting for the data from each individual plot. Correlation coefficients also were calculated using the three-plot mean for each genotype. Data for each planting were normalized using the mean and sD for each

Table 1. Correlation coefficients ( $r$ ) for individual plot harvest data between first harvest season and second season for six raspberry plantings.

\begin{tabular}{lcccccc}
\hline \hline Harvest & \multicolumn{7}{c}{ Year planting established } \\
\cline { 2 - 7 } data & 1987 & 1988 & 1989 & 1990 & 1991 & 1992 \\
\hline Fruit rot & -0.19 & 0.24 & 0.14 & $0.58^{* *}$ & $0.36^{*}$ & $0.34^{* *}$ \\
Yield & 0.32 & 0.14 & $0.31^{*}$ & $0.71^{* *}$ & -0.01 & $0.50^{* *}$ \\
Fruit firmness & $0.64^{* *}$ & $0.53^{* *}$ & $0.41^{* *}$ & $0.55^{* *}$ & $0.38^{*}$ & $0.44^{* *}$ \\
$\begin{array}{l}\text { Fruit mass } \\
\text { Midpoint of }\end{array}$ & $0.75^{* *}$ & $0.84^{* *}$ & $0.76^{* *}$ & $0.89^{* *}$ & $0.81^{* *}$ & $0.65^{* * *}$ \\
$\quad$ harvest & $0.82^{* *}$ & $0.80^{* *}$ & $0.71^{* *}$ & $0.79^{* *}$ & $0.85^{* *}$ & $0.87^{* *}$ \\
n & 33 & 39 & 51 & 24 & 39 & 72 \\
\hline
\end{tabular}

${ }^{*},{ }^{* *}$ Correlation coefficient significant at $P=0.05$ or 0.01 , respectively. 
planting, and the correlation coefficient calculated between the harvest data in the first and second harvest seasons for all plantings were combined.

\section{Results and Discussion}

The second harvest season averaged $48 \%$ greater yield, $96 \%$ more fruit rot, $9 \%$ larger fruit, and $6 \%$ firmer fruit. The midpoint of harvest was $1.6 \mathrm{~d}$ earlier than for the first harvest season. There were significant genotype, year, and genotype $\times$ year effects for all

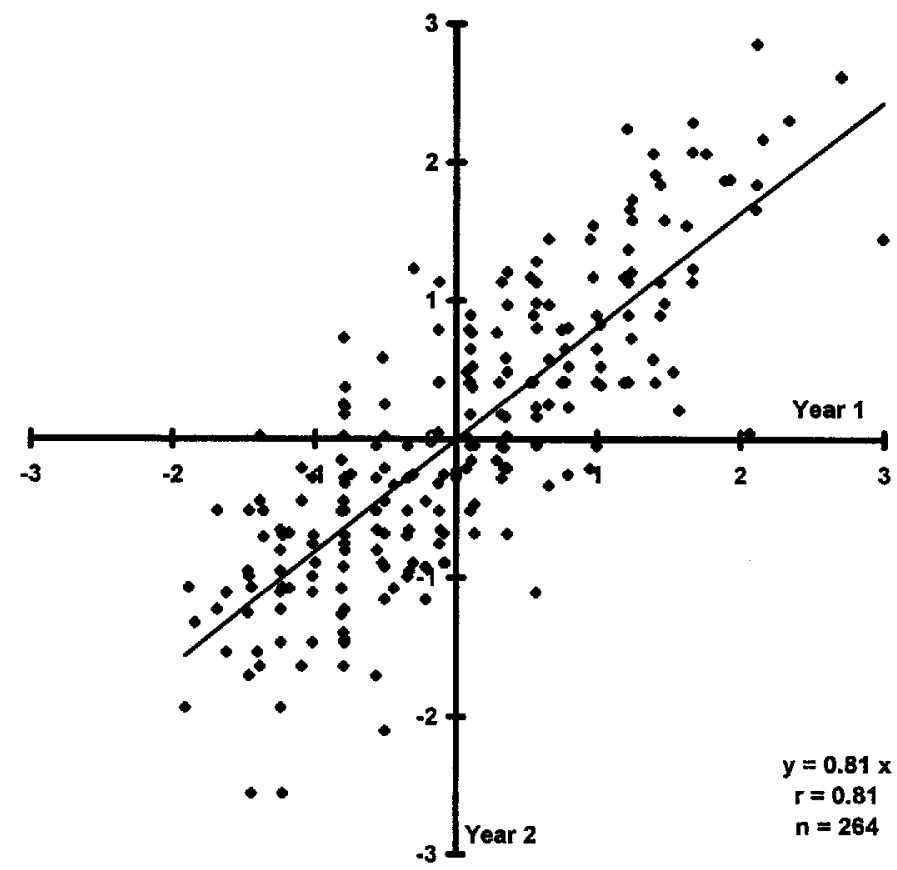

Fig. 1. Scatter diagram of the normalized midpoint of harvest of individual raspberry plots between the first harvest season and second season.

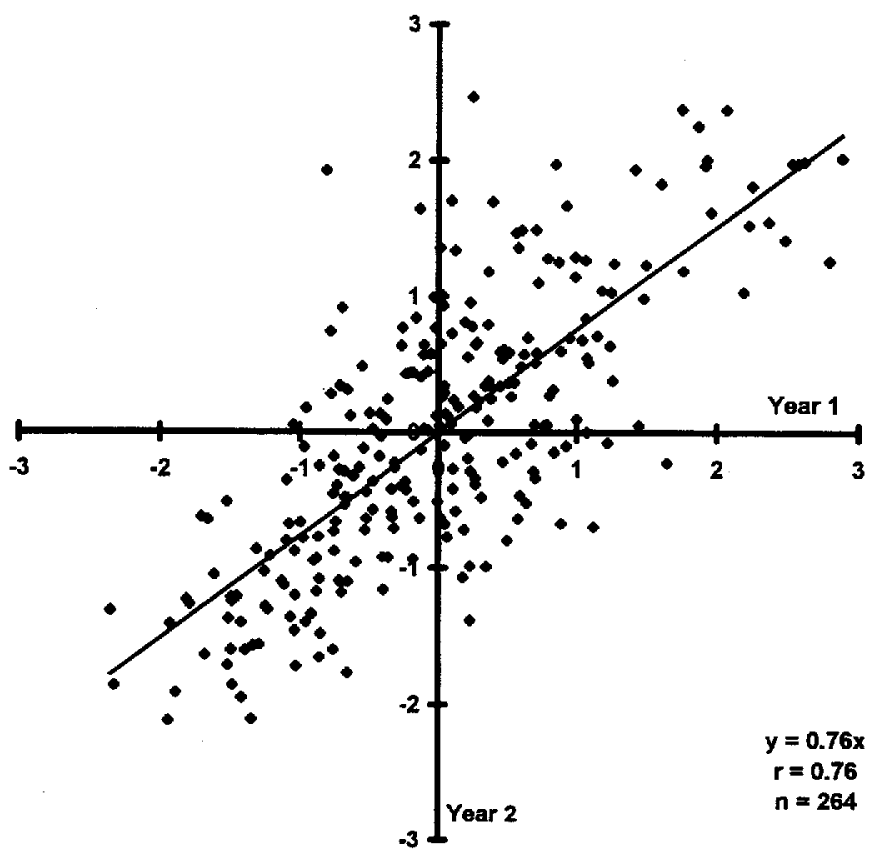

Fig. 2. Scatter diagram of the normalized fruit mass for individual raspberry plots between the first harvest season and second season. variables $(P<0.0001)$. When each planting was analyzed individually, there were significant genotype effects $(P<0.05)$ for all plantings and variables except for fruit rot in the planting established in 1989. There were significant year effects $(P<0.05)$ for yield and fruit firmness for all plantings and for five of six plantings for fruit rot, fruit mass, and midpoint of harvest. There were significant genotype $\times$ year effects $(P<0.05)$ for yield and fruit firmness for four of six plantings and for fruit rot, fruit mass, and midpoint of harvest for five of six plantings.

The correlation coefficients varied each year and differed for each trait (Table 1). However, there was no clear association between the value of the correlation coefficients and the size of the genotype, year, or genotype $\times$ year effects.

The most important information from evaluating the consistency of data is identifying the consequences of decisions in the first harvest season. If the data in a scatter plot are along a diagonal with a large $r$, as with the data for midpoint of harvest (Fig. 1) or fruit mass (Fig. 2), decisions can reliably be made on the first year data. A genotype with early or late ripening fruit usually would have fruit with a similar ripening time in the second season. However, the relationship was weaker for fruit firmness (Fig. 3), fruit rot (Fig. 4), and yield (Fig. 5). For yield (Fig. 5), the desirable genotypes are those that have large positive values in both years. Those that have negative values in both years should be discarded. Identifying these genotypes early in the evaluation process, would result in efficiencies in evaluation. Genotypes that have values in the other quadrants of the scatter plots represent evaluation problems. They may represent genotypes that have large yields only in specific environments, are susceptible to disease, or are slow to establish. The most serious difficulties are those genotypes that have negative values in the first harvest season and positive values in the second season. If all genotypes with values below the mean were discarded after the first season, genotypes with high yields in the second season could be eliminated. Potentially valuable material could be discarded.

One-hundred twenty-six plots ( $48 \%$ ) had yields above the mean

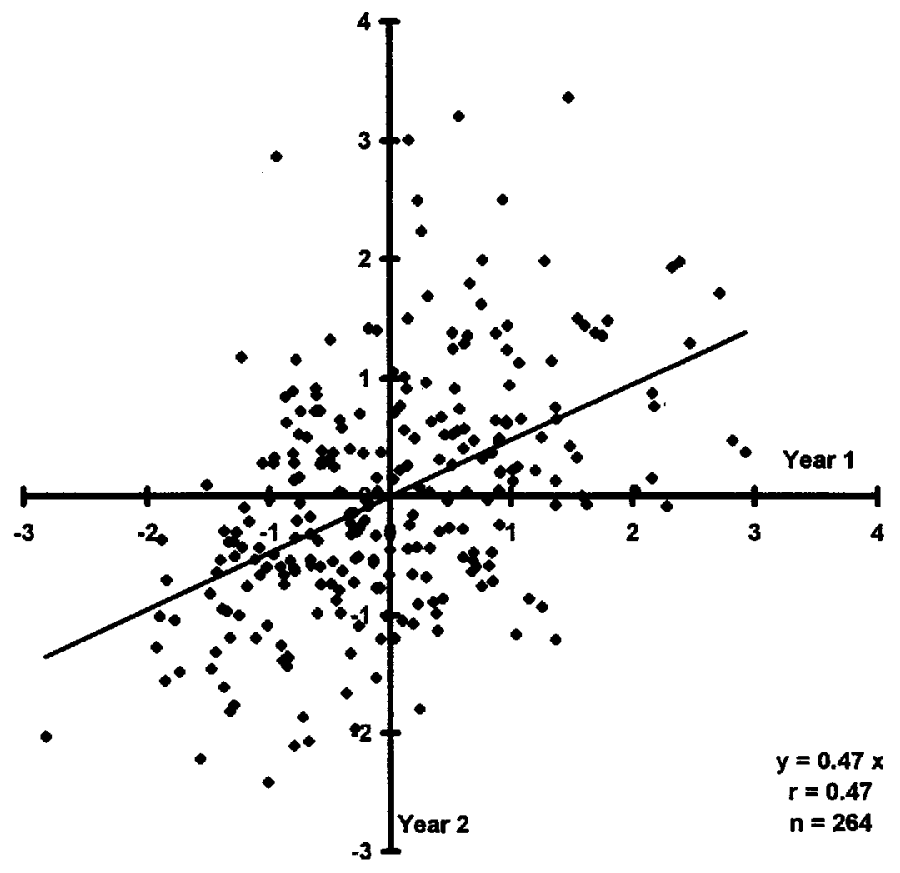

Fig. 3. Scatter diagram of the normalized fruit firmness for individual raspberry plots between the first harvest season and second season. 
(positive values) in the first season (Fig. 5). Seventy-three plots (28\%) had positive values in both seasons. However, there also were a large number of plots $(21 \%)$ that had negative values the first season and positive values the second. Some of these plots had high yields in the second season and could represent valuable genotypes that could be discarded prematurely. This result points out the risk of discarding a genotype based on the first harvest season. 'Chilcotin' is a genotype that could potentially be discarded based on the first harvest season. In all four plantings, the mean for 'Chilcotin' was below the mean for the first harvest season and above the mean for the second season.

Although the scatter plots (Fig. 1-5) were based on individual plot data, most evaluation decisions are based on replicated plot data. The scatter plot for yield of each genotype normalized with the mean and SD of the genotype means in that planting is given in Fig. 6. Replication did not greatly improve consistency of the data. Similar results were obtained for the other variables (data not shown).

The low correlation coefficients between the yield in the first year and the second year may be the result of the plots not attaining full size before the first harvest season. The canes in the third growing season were generally shorter and thinner than the canes in the same plots in the fourth growing season (personal observation). The $48 \%$ increase in yield from the first harvest season to the second also indicates that the plants may not have been fully established. The 1991 selection trial was harvested for a third time in 1995. The yield of this planting did not continue to increase with increasing time. The average yield increased $51 \%$ from the first season to the second and then decreased $13 \%$ from the second to the third season. The correlation coefficient for yield for this planting was greater between the second and third seasons $(r=0.53, \mathrm{n}=39)$ than that between the first and second season $(r=-0.01, \mathrm{n}=39$ ); however, this correlation coefficient between second and third seasons was similar to correlation coefficients between the first and second seasons for other plantings (Table 1).

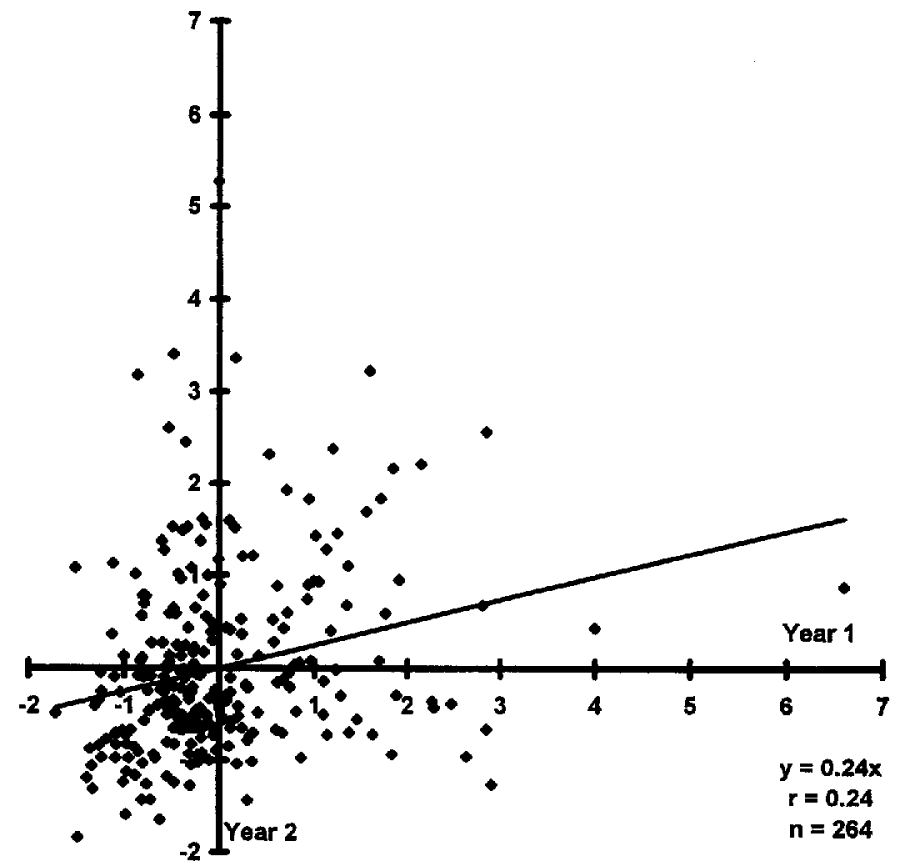

Fig. 4. Scatter diagram of normalized fruit rot for individual raspberry plots between the first harvest season and second season.
Evaluating a planting for 3 years may provide a better evaluation of the yield than a 2-year evaluation; however, it also requires more resources than two seasons. For the 1991 planting, the correlation coefficients between each individual year and the 3 -year total was $r=0.59,0.70$, and 0.84 for the first, second, and third harvest seasons, respectively. The correlation coefficient between the 2-and 3-year totals was $r=0.91(n=39)$. Based on this one planting, it appears that little additional information is gained by collecting yield data in a third harvest season.

The information in our study was based on harvest data from replicated plantings of selections and cultivars. The information from these planting suggests that, although decisions can be made

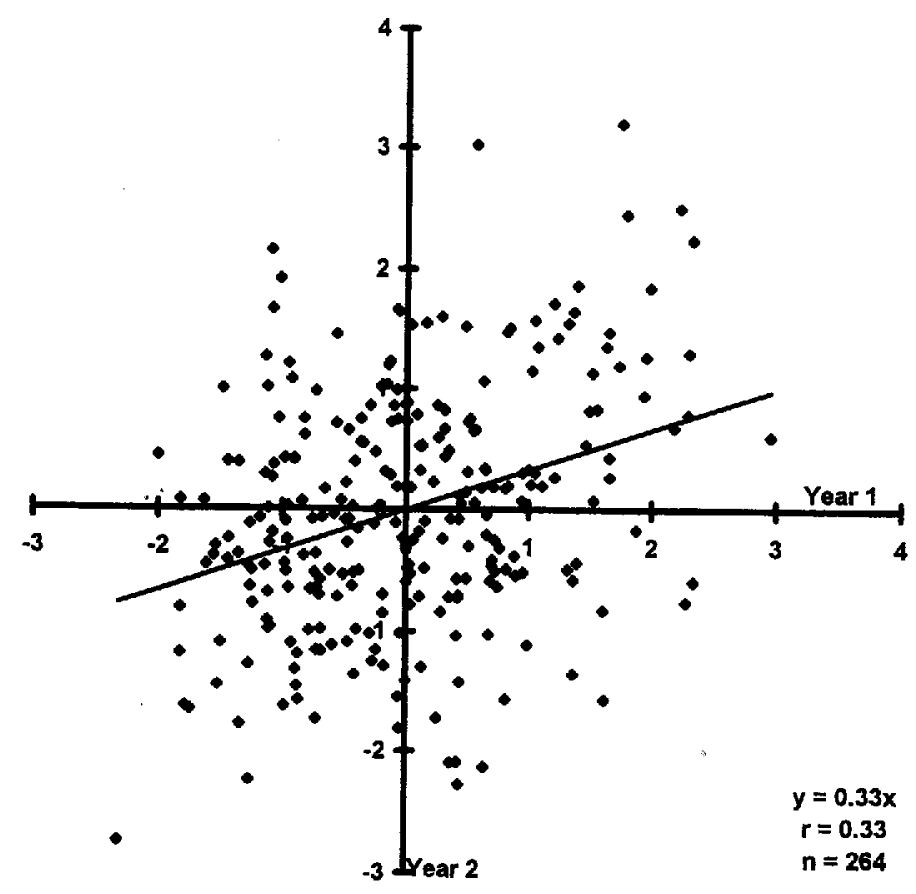

Fig. 5. Scatter diagram of the normalized yield for individual raspberry plots between the first harvest season and second season.

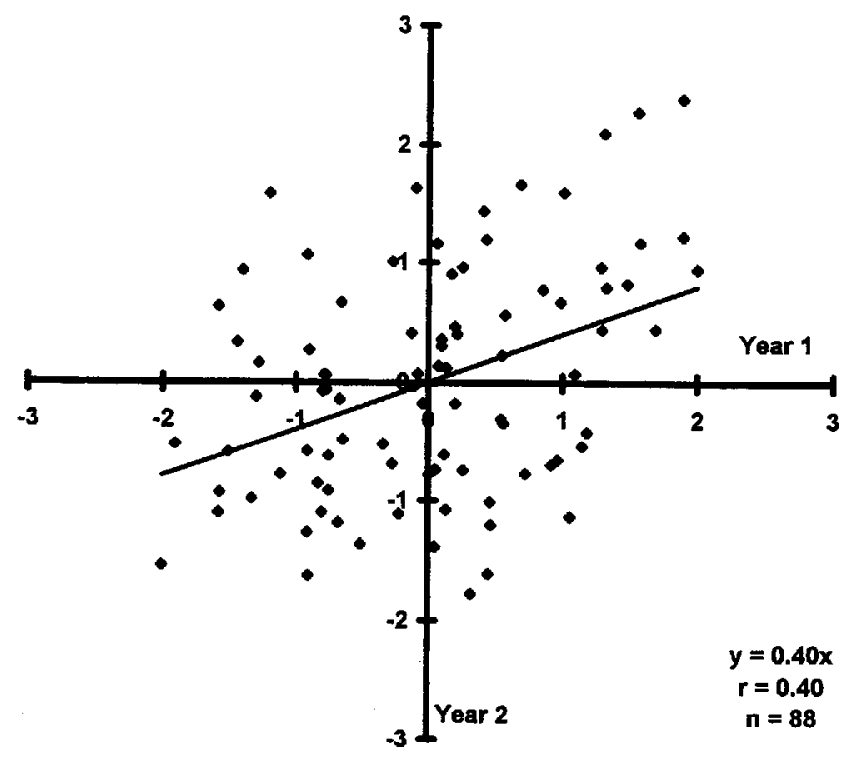

Fig. 6. Scatter diagram of the normalized yield based on three plot means for each genotype between the first harvest season and second season. 
about fruit mass and harvest season based on the first harvest season, evaluation for yield may not be accurate based on the first harvest season. This suggests that seedlings should remain in the field for at least two fruiting seasons. This inconsistency of yield data also would apply to cultural and physiological studies and recommendations should be based on $>1$ year of data.

\section{Literature Cited}

Dale, A. and H.A. Daubeny. 1985. Genotype-environment interactions involving British and Pacific Northwest red raspberry cultivars.
HortScience 20:68-69.

Fejer, S.O. 1973. Genotype $\times$ year interactions and ecovalence in raspberry selection. Can. J. Genet. Cytol. 15:226-229.

Moore, P.P., J.A. Robbins, and T. Sjulin. 1989. Harvest comparison of ten Willamette clones. Acta Hort. 262:387-390.

Robbins, J.A. and T. Sjulin. 1986. A comparison of two methods for measurement of fruit strength in red raspberry. HortScience 21:1054 1055.

Scheer, William P.A., and Ralph Garren. 1987. Commercial Red Raspberry Prod. Pacific Northwest Coop. Ext. Bul. 176. 